\title{
Da crise do sujeito à superação da confissão clínica
}

\section{The crisis of the subject to overcome clinical confession}

\author{
Alexandre Marques Cabral* \\ Universidade do Estado do Rio de Janeiro - UERJ, Rio de Janeiro, Rio de Janeiro, \\ Brasil
}

\begin{abstract}
RESUMO
O presente artigo objetiva inicialmente assinalar como Ana Maria Calvo de Feijoo, no livro A existência para além do sujeito, inscreve a noção de existência, pertencente ao pensamento fenomenológico de Martin Heidegger, como eixo em torno do qual gira uma nova proposta para a prática clínica em psicologia. Em um segundo momento, deve-se dizer por que sua proposta desconstroi o caráter confessional norteador das práticas clínicas tradicionais na psicologia. Para tanto, o texto reconstruirá operadores conceituais presentes na obra de Feijoo que viabilizem alcançar tais objetivos, além de explicitar certos pressupostos tacitamente presentes em seu pensamento que viabilizem as propostas aqui almejadas. Neste sentido, será necessário mostrar como a noção heideggeriana de existência subsidiada pelo conceito husserliano de intencionalidade desconstroi 0 conceito tradicional de verdade, pressuposto de toda prática confessional da clínica tradicional, prática esta que sempre imprimiu na psicologia as marcas da moralidade.
\end{abstract}

Palavras-chave: existência; sujeito; clínica; confissão.

\begin{abstract}
The present article aims firstly at highlighting the way (how) Ana Maria Calvo de Feijoo uses the notion of Existence in her book The existence beyond the subject. Such notion belongs to the phenomenological thought of Martin Heidegger, as an axis around which a new proposal for the clinical practice in psychology rotates. Secondly, the article focus on showing why her proposal deconstructs the leading confessional character of the traditional clinical practices in psychology. In order to reach its target, the text not only rebuilds the conceptual operators found in Feijoo's work, which make the goal possible to be reached, but it also makes explicits some principles present in her thought. To do so, it must be explained how the Heideggerian notion of existence and the Husserl concept of intentionality deconstruct the tradicional concept of truth. Such concept designs every confessional practice in traditional clinic. This is the practice which has always marked psychology with morality..
\end{abstract}

Keywords: existence; subject; clinic; confession. 


\section{Introdução}

O último livro de Ana Maria Lopez Calvo de Feijoo - A existência para além do sujeito - é o objeto de tematização do presente artigo cujo objetivo primário é mostrar, por meio de uma abordagem críticoreconstrutiva, como a autora, ao inscrever a existência como eixo de uma nova proposta para a clínica psicológica, desconstrói o caráter confessional norteador das práticas clínicas tradicionais e, assim, operacionaliza o procedimento destrutivo de matriz heideggeriana na psicologia de orientação fenomenológico-existencial. Para tanto, será necessário reconstruir alguns pressupostos hermenêuticos norteadores da abordagem de Feijoo, além de explicitar alguns conceitos utilizados pela autora na estruturação de seu pensamento. Deve-se observar, antes de tudo, que a plausibilidade do presente artigo se mostra sobretudo pelo fato de a autora em questão ser, no Brasil, uma das pioneiras em tal abordagem psicológica, produzindo, ao longo de sua trajetória acadêmica, diversas pesquisas importantes para a renovação do pensamento psicológico neste pais. A obra em questão parece ser fruto maduro de suas reflexões e acuradas pesquisas nesta área da reflexão da psicologia, o que assinala, consequentemente, 0 seu lugar de destaque na literatura da psicologia com bases fenomenológico-existenciais.

\section{A crise dos supósitos metafísicos e o horizonte hermenêutico de $A$ existência para além do sujeito.}

O livro que ora vem a lume - $A$ existência para além do sujeito possui o mérito de ser introdutório. É de admirar, entretanto, que isto seja um mérito, pois, como sabido, é lugar-comum considerar toda introdução uma facilitação, o que, em um primeiro momento, parece ser sinal de pedantismo, uma vez que aparenta julgar e condenar o leitor a ser aquele que por si só é incapaz de interpretar universos semânticos dotados de certa complexidade. Isto também implica em considerar o (a) autor (a) da obra como aquele (a) que é dotado (a) de capacidades intelectuais superiores às do leitor, o que fornece a ele (a) certa superioridade na relação com o tema em questão, se comparado (a) com aquele (a) que o (a) lê. Por outro lado, a lógica mercadológica, na ânsia de venda a todo custo, ânsia esta que corresponde à dinâmica inerente ao capitalismo, inscreveu na "literatura acadêmica", em grande parte, o selo da "introdução". Livros introdutórios são quase sempre garantia de venda e de acúmulo de capital. Isto transformaria $A$ existência para além do sujeito em fruto do oportunismo da autora e da editora, ambos ávidos por vendagem a qualquer preço. A despeito destes significados ligados ao termo "introdução", o caráter introdutório aqui assinalado 
possui certa peculiaridade. Trata-se do significado que emerge do termo latino introducere, raiz do verbo português introduzir, qual seja, lançar para dentro de ou enviar para o interior de... Mas, para dentro de que Feijoo nos lança? O subtítulo do livro nos dá uma pista: "A crise da subjetividade moderna e suas repercussões para a possibilidade de uma clínica psicológica com fundamentos fenomenológico-existenciais". O livro nos envia, então, para o universo semântico da crise da subjetividade e, a partir dele, desvela o horizonte hermenêutico de uma nova possibilidade de realização da clínica psicológica. Ora, cabe neste momento perguntar: por que a autora fala de uma tal crise da subjetividade? Até que ponto esta crise é condição de possibilidade de uma nova prática clínica na psicologia contemporânea? Por que a abordagem fenomenológicoexistencial aparece, para Feijoo, como "linha de fuga" da crise da subjetividade? Como se dá esta linha de fuga? Será que é possível "fugir" da subjetividade?

Se Feijoo pensa a crise da subjetividade como condição de possibilidade da gênese de novas possibilidades da prática clínica em psicologia, é porque ela concebe o termo crise a partir de dois sentidos co-pertencentes. Por um lado, a crise mencionada assinala certa derrocada do paradigma da subjetividade pertencente à tradição. Como derrocada, a crise nada mais é que a dissolução do poder de estruturação do horizonte hermenêutico a partir do qual algo assim como a subjetividade possuía força de persuasão no Ocidente. Por outro lado, tal derrocada descortina outro horizonte interpretativo que não somente desafia o pensamento, como esclarece o lugar de onde a subjetividade auriu suas forças. Neste sentido, está em jogo o significado áureo do verbo grego krinéin, a saber, discernir. Todo discernimento se perfaz por meio da visualização ou esclarecimento do que está efetivamente em jogo. Por meio desta clareza, a decisão pode ser tomada. No caso da crise assinalada por Feijoo, ela leva ao aclaramento da subjetividade, à medida que ilumina sua condição de possibilidade e assinala suas insuficiências. Ao mesmo tempo, esta visualização abre o campo para uma tomada de posição por parte da prática clínica. A crise, portanto, não é degenerativa somente, mas, sobretudo, regenerativa, porquanto inscreve novas possibilidades na psicologia outrora obscurecidas pela absolutização da subjetividade moderna.

Entretanto, a crise referida não é somente um ínterim que precede a irrupção de um novo modelo explicativo do homem e da totalidade do real. O que Feijoo chama de crise da subjetividade, que possui repercussões diretas e radicais na psicologia, é signo da crise do modo mesmo como se consolidaram e emergiram os modelos explicativos da tradição. Com tal crise, ganha clareza o modo ocidental de posicionamento teórico-prático dos comportamentos em geral e do mundo como um todo. Por ser um livro "introdutório", $A$ 
existência para além do sujeito nos insere no cerne da crise ocidental. $\mathrm{Na}$ introdução do livro, Feijoo assinala, de diversos modos e por meio da menção a várias correntes de pensamento, que a crise da subjetividade se identifica com a crise da substancialização do eu, ou seja, dito de modo mais radical, a crise refere-se antes de tudo à metafísica da presença (Cf. FEIJOO, 2011, p. 11-24). Ainda que tais noções possuam uma complexidade que não cabe aqui ser analisada, elas deixam vir à baila a originariedade do horizonte hermenêutico que sustenta a fala de Feijoo. Não se trata de um livro que tem a crise da subjetividade como tema privilegiado de pesquisa. Antes, a obra assume a crise como condição transcendental - já que aparece como condição de possibilidade - de sua fala, o que significa dizer que Feijoo aquiesce ao desafio de (re) pensar a psicologia clínica a partir de um horizonte interpretativo - e de conceitos aí nascidos que irrompe justamente desta crise. Cabe, então, perguntar: de que crise se trata? Que horizonte se abre por intermédio dela?

Pode-se afirmar que o pensamento contemporâneo, que aqui deve ser identificado com aquele que nasce em meados do século XIX sobretudo com Kierkegaard e Nietzsche, é essencialmente marcado por uma crise de raízes ontológicas e não somente morais, ainda que não se deva desconsiderar o problema moral que aí se forma. Tratase de uma crise mais profunda que aquela que tornou-se ultimamente lugar-comum na mass media. Por causa dela as demais crises são somente signos e não causas. A crise referida diz respeito à dissolução dos esteios meta-empíricos que sempre sustentaram os discursos mais variados no Ocidente, além da dissolução do caráter mesmo destes discursos, que sempre se determinaram como metanarrativas muito peculiares. O Ocidente sempre produziu discursos dos mais variados sustentados por instâncias ontológicas imunes ao devir, o que significa dizer que o Ocidente sempre foi debitário de algum tipo de metafísica da presença. Alguma presença constante, ou seja, previamente dada fornecia a base para a inteligibilidade dos múltiplos fenômenos que compõem o real. Por isso, antes de visualizar o que quer que seja, o pensamento ocidental contava com a vigência já per-feita (isto é, previamente constituída) de uma instância ontológica que garantisse o caráter multifacetado dos entes em geral. Por ser condição de possibilidade de todo devir possível e por garantir a inteligibilidade do todo, tal instância foi identificada com a noção de fundamento. Como fundamento, ela é suposta, ou seja, sub-posta, no sentido de que, antes de nos voltarmos para a efetividade de um fenômeno, já posicionamos e concebemos algo como subjacente ao fenômeno em questão. Esta sub-posição (suposição) nada mais faz que assinalar a presença previamente dada - por isso, uma presença constante - de um supósito. Em outras palavras, o pensamento ocidental sempre se caracterizou por contar com uma instância ontológica sub-jacente como fundamento 
dos entes em geral. O que subjaz pode ser dito em latim subjectum (sujeito), que se identifica inteiramente com a noção também latina de substantia (o subjacente). Como tal instância ontologicamente está posicionada "para além" do devir e da singularidade dos fenômenos, os discursos que sempre pretenderam dar conta dela se caracterizaram por ser dotados de universalidade e por pretenderem subsumir (subjugar) o múltiplo por meio do uno que com ele não se identifica. Devido ao fato de pretender se estruturar por meio de um deslocamento do múltiplo em direção ao uno ou de uma saída do devir em direção ao imutável, o discurso que sempre visou descrever o supósito dos entes é caracterizado a um só tempo como metanarrativa metafísica. Pode-se dizer então que o pensamento ocidental, desde a sua aurora até o seu ocaso, determinou-se pelas sucessivas tentativas de descrever a "subjetividade" dos fenômenos, para que estes pudessem ser fundamentados e tivessem assegurada sua inteligibilidade derradeira. Por isso, o Ocidente sempre supôs um corte ontológico no real, que os gregos (sobretudo Platão) chamaram de chorismós. A cisão do real funda uma compreensão binária do mundo, onde diversas oposições são possíveis enquanto são consideradas variações do mesmo tema: as dicotomias metafísicas sempre reproduziram e reinscreveram a relação fundamento/fundado, sendo que o primeiro dos pólos foi considerado o substrato ontológico condicionador e justificador do segundo. Considerou-se tal pólo como previamente constituído - por isso o seu caráter substantivado. Ora, se a crise que nos assola diz respeito à estruturação das meta-narrativas que vieram estruturando o Ocidente, então, o que está em jogo nela é a derrocada do modo mesmo como o Ocidente compreendeu o real até então. Como entendê-la?

Nietzsche assinalou a crise que nos acomete com a famosa expressão "Deus está morto". Apesar de a morte de Deus aparecer em diversas páginas significativas de sua obra, a passagem mais conhecida, presente no aforismo 125 de A gaia ciência, diz expressamente que a causa mortis de Deus é deicídio. Deus foi assassinado não por um homem, mas pelo homem ocidental na modernidade de sua história: "Para onde foi Deus?, gritou ele, 'já lhes direi! Nós o matamos vocês e eu'. Somos todos seus assassinos! Mas como fizemos isso? Como conseguimos beber inteiramente o mar? Quem nos deu a esponja para apagar o horizonte? Que fizemos nós, ao desatar a terra do seu sol?" (NIETZSCHE, 2002, § 125). Deus morreu assassinado por nós. Não se trata de um grito a mais no coro dos ateísmos ocidentais, que nada mais são que um tipo de teísmo invertido parido no seio da modernidade. Como percebeu Heidegger: "O dito 'Deus morreu' significa: o mundo supra-sensível está sem força atuante. Ele não irradia nenhuma vida" (HEIDEGGER, 2002, p. 251). A morte de Deus é a imagem nietzschiana para caracterizar a crise da metafísica 
enquanto meta-narrativa que descreve hipóstases ontológicas que funcionam como fundamento último dos entes em geral. O homem ocidental, devido ao desdobramento de sua história, assassinou a possibilidade de acessar estas hipóstases e de perpetuar o tipo de universalidade inerente às meta-narrativas que daí emergiam. Disto decorre a inviabilidade da manutenção das subjetividades que sempre estruturaram as cosmovisões ocidentais. Se foi dito que a obra de Feijoo nasce de um determinado aquiescimento à crise pela qual o Ocidente passa e se dissemos também que esta crise possui um duplo registro - a saber, crise como dissolução da metafísica e das meta-narrativas que lhe serviam de suporte e crise como regeneração do pensamento, não mais marcado pela tentativa de descrever hipóstases ontológicas -, deve-se inquirir como Feijoo movimenta-se nesta crise. Até que ponto $A$ existência para além do sujeito é uma resposta a esta crise no âmbito da psicologia?

\section{Da dissolução das hipóstases metafísicas à necessidade da destruição hermenêutica: a apropriação da caráter histórico do real}

Com a crise das hipóstases ontológicas e das meta-narrativas que intentaram descrevê-las, o Ocidente se deparou com, pelo menos, dois elementos que passaram a determinar essencialmente os caminhos do pensamento em geral. O primeiro deles é a inviabilidade de se sustentar o que se pode denominar de caráter especular da verdade. A verdade de algum modo sempre foi entendida como um espelho (speculum) que reflete o ente tal qual ele em si mesmo é. Em sua Questão disputada sobre a verdade (De veritate), Tomás de Aquino afirma ser a verdade "conveniência do ente ao intelecto" (2002, p. 149). O ente convém ao intelecto, à medida que o que ele é (sua essência) é assimilável pelo intelecto humano, que, por poder apreender ou apropriar-se da quididade do ente, "de certo modo é todas as coisas" (hoc autem est anima, quae quodammodo est omnia) (Ibidem, p. 147). Por isso a famosa definição da verdade como "a adequação da coisa e do intelecto" (Ibidem, p. 149). Veritas est adaequatio intellectus et res - eis a fórmula clássica que assinala o caráter especular da verdade. A verdade é aí a pretensão de o discurso espelhar inteiramente o que o ente é em si mesmo. Independentemente do modo como se pensou a relação entre intellectus e res, a questão é que a verdade que daí emerge sempre supôs dizer o "em si" do ente, o que indica uma pré-compreensão ontológica de que o real em si mesmo é estruturado por algum tipo de hipóstase, seja a da coisa objetivamente dada ou a consciência representadora. Se Deus morreu, então, a verdade não pode caracterizar-se por ser especular. Não há "em si" apartado das 
relações que formam de algum modo o horizonte de aparição dos entes para o homem. Em outros termos: o em-si é de algum modo para-si (Cf. CASANOVA, 2006, Introdução). Consequentemente, os pólos da relação não geram a relação, mas, antes, são gerados por ela, ou seja, a relatio é ontologicamente "anterior" aos relata. Sem entrar neste momento nos pormenores fenomenológicos da ideia de relação - que na fenomenologia em geral se identifica com a noção de intencionalidade -, deve-se observar que um outro elemento desafiador invade o pensamento contemporâneo, a saber, a ideia de história. Com a derrocada das hipóstases metafísicas, o pensamento se vê às voltas com o caráter histórico do real. Se a morte de Deus pode conjugar-se com a desubstancialização do real, então, ela abre as portas para pensar seu caráter verbal. Acaba-se, então, aquela pretensão denunciada por Nietzsche de todo filósofo clássico: "Eles acreditam que desistoricizar uma coisa, torná-la uma sub specie aeterni, construir a partir dela uma múmia, é uma forma de honrá-la. Tudo o que os filósofos tiveram nas mãos nos últimos milênios foram múmias conceituais; nada de efetivamente vital veio de suas mãos" (NIETZSCHE, 2000, p. 25). Pensamento e história estão congenitamente relacionados, o que significa dizer que todo conceito nasce condicionado por horizontes históricos. Pode-se destacar aí duas grandes implicações para o pensamento.

A primeira implicação refere-se ao fato de que a desubstancialização do real engendra a historicização da condição humana e da totalidade do ente. Não somos nada para além do desdobramento do nosso ser, o que significa dizer que somos verbos conjugados no gerúndio. Não sendo formados por quaisquer hipóstases ontológicas, somos o que estamos sendo. Nosso ser é dotado de uma "elasticidade ontológica" congênita. Por outro lado, não somos mônadas autossuficientes cerradas em si, que se relacionariam acidentalmente com a totalidade do mundo. A unidade com a totalidade sempre já aconteceu, pois o caráter relacional do real acima mencionado não nos permite pensar em qualquer solipsismo humano. Consequentemente, o elemento histórico que nos estrutura também determina a totalidade do ente que se articula essencialmente conosco. Entretanto, esta historicidade não se identifica com a ideia ainda em voga de que viver é paulatinamente dissolver-se até o colapso da existência presente no falecimento do vivente humano. Neste último sentido, a história seria composta pela evaporação de instantes diversos que de algum modo se relacionaram conosco um dia. O que fomos não teria relação essencial com o que somos, a não ser enquanto causa eficiente, 0 que significa dizer que nosso passado seria externo a nós mesmos. Ora, a gerundização do real subverte justamente esta ideia de história. Somos por meio do passado que ainda é vigente em nosso ser. O passado não se despede do homem. Em sua caracterização originária, é o passado que precede seus passos, como Heidegger 
assinalou no parágrafo 6 de Ser e tempo (Cf. HEIDEGGER, 2006, § 6). Por isso, o passado não é algo que temos, mas aquilo que somos. Isto gera a segunda implicação para o pensamento, qual seja, a necessidade de assumir a tradição da qual ele sempre faz parte. Todo pensamento é tradicional por essência. É tradicional no sentido de que é o passado que fornece a base de sustentação de suas investidas, servindo de condição de possibilidade para sua realização. Vale lembrar que o verbo latino tradere significa legar, transmitir. 0 pensamento é tradicional porque ele sempre se perfaz por meio do legado do passado que o condiciona. Neste sentido, a assunção da crise da metafísica ocidental engendra o desafio de se pensar historicamente. Como disse Karl Marx, na abertura de seu Os 18 brumário de Luís Bonaparte:

\begin{abstract}
Os homens fazem sua própria história, mas não fazem como querem; não a fazem sob circunstâncias de sua escolha e sim sob aquela com que se defrontam diretamente, legadas e transmitidas pelo passado. A tradição de todas as gerações mortas oprime como um pesadelo o cérebro dos vivos. É justamente quando parecem empenhados em revolucionarse a si e às coisas, em criar algo que jamais existiu, precisamente nesses períodos de crise revolucionária, que os homens conjuram ansiosamente em seu auxílio os espíritos do passado, tomando-Ihes emprestado os nomes, os gritos de guerra e as roupagens, a fim de apresentar-se nessa linguagem emprestada (MARX, 1988, p. 7).
\end{abstract}

Por um lado, o pensamento deve assumir a história da qual faz parte. De outro modo, ele não pode ter a pretensão de preservar o caráter especular da verdade, retratando de modo mais "fiel" o que o real hipostasiadamente é em si mesmo. Deste modo, o diálogo com a tradição - que é inevitável - deve assumir um novo horizonte hermenêutico, que não preserve o modo metafísico de inquirição dos entes. É justamente isto que é realizado por Feijoo em $A$ existência para além do sujeito. A obra se estrutura através de um diálogo com a tradição e de uma renovação no horizonte de tematização da psicologia. É por isso que ela apropria-se de Husserl e Heidegger e assume o procedimento metodológico destrutivo deste último. Por que esta escolha? Até onde um procedimento intitulado "destruição" pode favorecer a produção de um discurso "positivo" renovador para a psicologia? A resposta a esta questão necessita de um esclarecimento prévio do arcabouço conceitual em que se move o livro de Feijoo.

\title{
40 esteio fenomenológico-existencial de Feijoo
}


A "positividade" presente no livro de Feijoo depende diretamente de sua apropriação dos pensamentos de Edmund Husserl e Martin Heidegger. São estes filósofos que fornecem o caráter positivo de todo exercício "destrutivo" que atravessa a obra. Ambos aparecem sobretudo no primeiro capítulo do livro - "Da consciência intencional em Husserl à desconstrução da subjetividade em Heidegger" - como desveladores de um outro horizonte hermenêutico diferenciado da metafísica da tradição. Importa à Feijoo a apropriação criativa de elementos fenomenológico-existenciais possibilitados por estes autores para encaminhar sua reinterpretação da clínica psicológica. No que diz respeito a Husserl, Feijoo destaca sua contribuição à critica da atitude natural, à desconstrução das hipóstases psicológicas, sua ideia de intencionalidade e a reconstrução do eu enquanto síntese de vivências intencionais (Cf. FEIJOO, 2011, p. 2534). Como se sabe, Husserl empreende uma critica veemente à atitude natural do homem, que concebe os entes em geral à luz do que se pode chamar de caráter empírico. Cotidianamente, entendemos serem os entes dotados de propriedades previamente constituídas, sejam estes entes humanos ou não. Esta posição ontológica tornou-se normativa no Ocidente, determinando o modo mesmo como as ciências e a filosofia interpretam o real. Com o advento das ciências humanas e com a tematização da subjetividade humana, as ciências acabaram por reificar o psiquismo humano, mediante uma abordagem explicativo-causal dos seus processos internos. Com isto, tornou-se comum o posicionamento de hipóteses investigativas como veículos de confirmação ou rechaçamento de teorias explicativas dos processos psíquicos. A crítica husserliana coloca em xeque justamente o pressuposto ontológico do caráter empírico dos entes em geral como sentido originário de seu ser. Não há originariamente empiricidade alguma nos entes. Um simples copo que vemos não é dotado de propriedades previamente definidas e hipostasiadamente presentes. Isto, para Husserl, já é fruto do olvidamento da dinâmica imanente da consciência e a fuga ou transcendentalização desta mesma imanência. Por isso a necessidade de empreender uma "redução fenomenológica" (HUSSERL, 1989, p. 25), entendida como recondução do conhecimento ao tópos onde um fenômeno vem a ser o que ele é. Como afirmou Husserl: "o genuíno sentido do princípio é a exortação constante a permanecer junto das coisas que aqui, na crítica do conhecimento, estão em questão, e não misturar os problemas aqui presentes com outros completamente diversos" (Ibidem, p. 26). As "coisas" se identificam em Husserl com os fenômenos e estes só podem ser apreendidos no seu campo de aparição, que nada mais é que o seu campo intencional. O cerne, portanto, do pensamento husserliano é justamente o conceito de intencionalidade e é ele o centro da tematização de Feijoo, no que concerne a Husserl, em seu livro. Por intencionalidade Husserl 
entende o fato de toda consciência já ser sempre consciência de... Isto indica, primeiramente, que os fenômenos psíquicos são estruturados de modo não posicionador. Nossa consciência já sempre está aberta para correlatos que ela mesma não "inventa". Este caráter de abertura marca a consciência com um elemento extático. Consequentemente, não existe consciência antes da relação onde um determinado fenômeno se dá. Um campo de aparição, portanto, já sempre se interpôs condicionando o aparecimento do fenômeno e da própria consciência humana. Tal campo é intencional porque ele possui uma dinâmica própria, que não é determinada pelo sujeito cognoscente e é por causa de sua dinâmica que apreendemos um ente de um determinado modo de ser e não de outro. Se Husserl coloca como princípio "permanecer junto das coisas", as coisas em questão se confundem com o campo intencional que determina um fenômeno como sendo o que é. Isto confere a todo ato de consciência o caráter da intencionalidade. A consciência, portanto, é sempre transcendente, caso a transcendência seja compreendida como exposição aos campos intencionais onde se determinam os fenômenos. Como afirma Feijoo: "Para a fenomenologia de Husserl, o psiquismo não possui nenhuma determinação prévia, nem mesmo um eu substancial. A consciência é, para este filósofo, transcendente, nunca se retém em si mesma, mas se vê projetada por seus próprios atos para o campo dos objetos correlatos" (FEIJOO, 2011, p. 31). Isto retira a pretensão de se considerar os entes por meio de categorias universais que desconsiderem a singularidade dos campos intencionais onde os fenômenos se constituem. Não se pode considerar um ente sagrado do mesmo modo como se considera um objeto científico qualquer. Isto é desconsiderar seu campo intencional. Estes campos, por sua vez, não são inventados pela subjetividade humana. Quando se dão, nós neles nos movemos segundo o que eles são. Disto emerge um novo modo de compreensão do "eu". O "eu fenomenológico" do qual fala Feijoo é composto por "vivências intencionais" (Ibidem, p. 33). Sem propriedades ontológicas previamente dadas, o eu nada mais é que síntese de vivências, vivências estas que caracterizam 0 desdobramento da consciência nos campos intencionais onde ela se move. Isto desconstrói qualquer pretensão de substancialização da interioridade humana e qualquer possibilidade de explicá-la por meio de teorias baseadas na ideia de causalidade. Em outras palavras: Feijoo encontra em Husserl o primeiro aliado para se pensar um eu destituído de empiricidade.

Por outro lado, como assinala o título do livro - A existência para além do sujeito -, Feijoo encontra no conceito de existência o cerne da condição humana, suspendendo, como fizera Heidegger, a própria consciência intencional de matriz husserliana. Por isso, não é à toa que Heidegger aparece como principal aliado da autora em seu 
projeto de renovação da clínica psicológica. Feijoo foca-se em alguns dos principais operadores conceituais da ontologia fundamental de Heidegger. Em toda sua abordagem deste pensador, na primeira fase de sua obra, o que está em jogo é o esclarecimento da dinâmica finita da existência do ser-aí humano. Por isso, a existência é o conceito-chave da apropriação que Feijoo realiza da analítica existencial de Heidegger. Como se sabe, o conceito heideggeriano de existência, ao contrário do que pode parecer, nada tem a ver com, por exemplo, a ideia tomista de actus essendi (ato de ser). Não indica o simples fato de que algo é, existe, está factivelmente presente. Antes, somente um ente existe: o ente que nós mesmos somos, o ser-aí. Por isso a sentença um tanto escandalosa, repetida quatro vezes em Ser e tempo: "A essência do ser-aí é a sua existência" (HEIDEGGER, 2006, § 9). Apropriando-se da ideia escolástico-cristã de que em Deus existência e essência são uma só e mesma coisa, Heidegger transpõe esta identificação para o ser-aí, este ente que, para ser, deve a cada vez relacionar-se compreensivamente com seu ser (Cf. Idem). Neste sentido, o ser-aí não possui uma essência que congrega diversas propriedades comuns a outros entes de sua espécie. Antes disto, sua essência é existência, enquanto existir significa ek-sistir, ser-arremessado-para-fora-de-si, jogado em direção ao horizonte histórico-mundano de realização de si. Como disse Heidegger em Conceitos fundamentais da metafísica (MundoFinitude-Solidão): "O ente que chamamos ser-aí é o ente de um gênero originariamente próprio, um ente que irrompe para ser. Deste ente, dizemos que ele existe, isto é, ex-sistit; que ele é na essência de seu ser um movimento para fora de si mesmo, sem, porém, abandonar a si" (HEIDEGGER, 2003, § 75). A ipseidade que é a nossa, portanto, não possui identidades absolutas. Nosso "si mesmo" se conquista performaticamente, o que significa dizer que nossa existência é temporal - tempus est homo (Cf. HEDEGGER, 2006, § 65). Se a existência subtrai do ser-aí propriedades ontológicas previamente dadas, ela o marca com o selo da nadidade, ao mesmo tempo que o obriga a ter de conquistar-se para ser quem é (Cf. Ibidem, $\S 9$ e 31). Somos, em outras palavras, poder-ser. O que somos é resultado do desdobramento de possibilidades de ser, que conformam relativamente a nadidade que nos constitui. Poder-ser e nadidade (ou negatividade) se identificam, exigindo que a assunção de possibilidades de ser engendre certa configuração ontológica em um ente marcado pela destituição de qualquer propriedade "empírica" (no sentido acima visto na fenomenologia husserliana).

Por sermos o nascer e o morrer de nossas possibilidades de ser, somos mortais. Em outras palavras: a finitude determina essencialmente o ser-aí que somos. Tal finitude não indica privação, por oposição à plenitude ontológica da infinitude divina. A finitude aparece por meio da mortalidade que é a nossa. Segundo Heidegger, 
não morremos porque falecemos. A morte não é, em sentido originário, o colapso da vida. Antes, a morte só se dá verbalmente, no morrer. Por isso, ela só pode ser uma possibilidade de ser do seraí. Enquanto possibilidade, a morte já determina o ser-aí enquanto horizonte existencial mais próprio de ser si mesmo (Cf. HEIDEGGER, 2006, § 53). Em outras palavras: a morte, enquanto possibilidade de ser, é antecipada pelo ser-aí, fornecendo a ele um horizonte peculiar para sua existência. Neste sentido, a morte é a possibilidade mais própria do ser-aí. É que ela destranca cada possibilidade de ser em sua transparência ontológica, isto é, enquanto tão-somente possibilidade de ser. Isto equivale a dizer que a partir do horizonte da mortalidade o ser-aí apropria-se do caráter finito de suas possibilidades, ao mesmo tempo que conquista a inteireza de seu ser. Inteireza não significa completude. Isto o ser-aí, por ser poder-ser, não pode ser. Entretanto, ele pode ser inteiramente segundo sua condição de poder-ser. É isto que se desvela a partir da mortalidade do existir. Por isso, a finitude identifica-se originariamente com o espaço próprio de realização da singularidade do ser-aí. Ser fin-ito significa, deste modo, ser dentro do limite (fim) de realização de seu ser mais próprio (Cf. Ibidem, §§ 58-62). Mortal, o ser-aí é propriamente temporal. Por isso, ele é segundo o viver e morrer de suas possibilidades, que se atualizam por meio da diversidade de seus comportamentos (Cf. FEIJOO, 2011, p. 39-44).

Após Feijoo explicitar em linhas gerais a relação entre ser-aí, poderser e finitude (mortalidade), sua atenção se direciona para as tonalidades afetivas do ser-aí. Estas, não sendo moções subjetivas ou afecções da alma, não são apêndices da condição humana, que poderiam ser extirpadas, para que o intelecto agisse de modo mais livre para atingir o mundo de modo mais objetivo. Antes, as tonalidades afetivas são responsáveis por desvelar o ente na totalidade para o ser-aí. Justamente por ser ek-sistente, o ser-aí não se relaciona com a totalidade que o mundo é senão por intermédio das tonalidades afetivas. Elas, a um só tempo, apresentam como o ser-aí está e como a totalidade do ente se desvelou para ele (Cf. HEIDEGGER, 2006, § 29). Como todo mundo em que o ser-aí é não é absoluto, pertence a ele o caráter histórico. Neste sentido, Feijoo se dá conta de um elemento importante na obra heideggeriana, que é o caráter histórico-epocal de algumas tonalidades afetivas específicas. Elas são tonalidades privilegiadas, uma vez que permitem vislumbrar o mundo em que estamos e o modo como no mais das vezes nele nos encontramos desempenhando nossa existência. Disto depende toda prática clínica, pois somente entendendo a relação entre ser-aí, finitude e mundo histórico pode-se compreender a especificidade das crises existenciais de ser-aí, que justificam a pertinência da clínica terapêutica. Com a elucidação das tonalidades afetivas, Feijoo conquista o solo hermenêutico para sua reinterpretação das práticas 
clínicas. Ela parte, portanto, do pressuposto de que o ente que somos é um poder-ser afetivamente (dispositivamente) articulado com o mundo histórico do qual faz parte, tendo que dar conta de sua finitude constitutiva. Justamente este solo identifica-se com a ideia de uma existência para além do sujeito. A partir disto, Feijoo entende o conceito moderno de sujeito, debitário da noção de subjectum da tradição metafísica, como uma concepção teórica do ente que somos que emerge da alienação de nossa condição mais própria. Esta base conceitual fornece a Feijoo o horizonte necessário para 0 empreendimento de sua desconstrução da prática clínica inerente à tradição.

\section{A desmoralização da psicologia e a desconstrução do caráter confessional de suas práticas clínicas na obra de Feijoo: considerações finais}

A desconstrução de Feijoo identifica-se inteiramente com a noção de destruição presente no parágrafo 6 de Ser e tempo. Deve-se observar entretanto que, apesar da autora não dedicar qualquer capítulo à tematização explícita da destruição, seu pensamento, desde a introdução até a conclusão, se constrói por meio de uma lida destrutiva com a tradição filosófico-psicológica, sobretudo no que concerne à prática clínica. Neste sentido, cabe perguntar: o que se entende por destruição? Se dissemos anteriormente que o livro de Feijoo possui um elemento claramente "positivo", como pode um termo aparentemente "negativo" - destruição - relacionar-se com esta positividade? Primeiramente deve ser observado que a destruição refere-se à imbricação já assinalada entre pensamento e história. O legado assumido pelo pensamento diz respeito a estruturas conceituais hipostasiadas ou hipostasiantes. No nosso caso, pensamos sempre enredados em uma malha conceitual debitária de pré-compreensões ontológicas que pensam o ser do real como supósito ou presença constante, que serve de fundamento metafísico dos entes em geral. Isto gera o perigo de desconsiderarmos as raízes dos conceitos que legamos e levarmos adiante tal alienação, ao produzirmos novos conceitos desconectados do lastro existencial de onde provêm. Como afirmou Nietzsche: "Os conceitos filosóficos individuais não são algo fortuito e que se desenvolve por si, mas crescem em relação e em parentesco um com o outro; embora surjam de modo aparentemente repentino e arbitrário na história do pensamento, não deixam de pertencer a um sistema (...)" (NIETZSCHE, 2005, § 20). O caráter sistemático dos conceitos, ao qual Nietzsche se refere, diz respeito à interdependência histórica de onde ele emergem. Se a nossa história se identifica com a história da metafísica, há sempre o perigo de 
reproduzirmos a tendência de almejar descrever, por meio de metanarrativas metafísicas, os supósitos dos entes, o que, à luz da morte de Deus, é inviável e, por isso, indesejável. A destruição heideggeriana nasce da necessidade de 0 pensamento assumir 0 legado conceitual que o condiciona, porém sem repetir o gesto metafísico que determinou este mesmo legado.

Para dar conta da destruição, Heidegger assume o desafio de buscar as "certidões de nascimento" (HEIDEGGER, 2006, § 6) das ontologias da tradição. A destruição, portanto, é primeiramente uma elucidação do "lugar" de onde nasceram os conceitos. Este lugar nada mais é que a estrutura existencial do ser-aí. No caso da metafísica, sua condição de possibilidade, ao menos na época de Ser e tempo, foi pensada por Heidegger como presente no modo impróprio de realização existencial do ser-aí, modo este para o qual os entes aparecem como dotados de propriedades previamente dadas, o que forma o horizonte de inteligibilidade metafísico dos mesmos. Com o exercício da destruição, Heidegger reinscreve os conceitos da tradição na estrutura do ser-aí, resignificando-os. Assim, não ficamos presos aos encurtamentos da tradição e podemos nos apropriar criativamente de seus elementos sem reproduzir o gesto metafísico que inicialmente os engendrou. Destruir é, portanto, desvelar as bases existenciais dos fenômenos, aclarando o "hoje" (Idem) em que se pensa, sem se deixar levar pelo modo mesmo como a tradição perguntou pelo ser dos entes em geral. Isto proporciona certa liberdade para o pensamento, uma vez que o libera para uma visada fenomenológica dos campos (intencionais) onde os pensamentos da tradição irromperam, o que favorece à superação dos encurtamentos legados historicamente pela filosofia, além de permitir reconstruir a tradição, percebendo, a um só tempo, os limites de seu modo de questionamento e apropriando-se criativamente de seus conceitos. Por um lado, Feijoo leva adiante a destruição heideggeriana ao assinalar a inviabilidade de perpetuar a subjetividade egóica da tradição (Cf. FEIJOO, 2011, Introdução). Tal subjetividade, por motivos já expostos, não dá conta do lastro existencial que determina a condição ontológica do ser-aí. Ao mesmo tempo, o diagnóstico de Feijoo quanto a esta subjetividade não é outro senão o fato de que ela nasce alienadamente, pois ela autonomizou-se de suas bases. Entretanto, a apropriação criativa implícita em seu exercício destrutivo (ou desconstrutivo) mostra-se na apropriação da prática clínica. Com base na Daseinsanalyse, Feijoo reinscreve a prática clínica nas bases fenomenológico-existenciais que sustentam os transtornos psicológicos em geral (Ibidem, p 57-87). Justamente isto injeta novas possibilidades na clínica e, consequentemente, novos desafios para a psicologia. Deve-se aqui destacar somente dois elementos da proposta de Feijoo à clínica explícita ou tacitamente 
presentes em $A$ existência para além do sujeito. Uma passagem da introdução do livro permite-nos assinalá-los:

(...) Tanto a Psicanálise quanto o Behaviorismo partem de
teorias que mapeiam a subjetividade ou estabelecem as leis
a partir das quais a subjetividade (comportamento) se
constitui, encontrando em seguida elementos psíquicos que
compõem essa subjetividade e que determinam o seu modo
de funcionamento. Cabe ao especialista psi dominar, por sua
vez, tal subjetividade e, assim, saber como fazer para
adaptar o homem ou reduzir suas tensões.
Assim, o especialista em Psicologia acaba por construir um
modelo teórico, seja dedutivo ou empírico, que retrata todo o
funcionamento psíquico nas suas referências de normalidade
e desvio. A partir destas elaborações complexas, então, ele
constroi teorias e técnicas, que vão garantir não só o domínio
do funcionamento psíquico, mas também o manejo do
profissional para obtenção de resultados "positivos" (FEIJOo,
2011, p. 19).

De acordo com Feijoo, as práticas clínicas na psicologia sempre pressupuseram a normatividade de modelos teóricos como posicionadores do modo de aparição do ser humano. Tanto a psicanálise quanto as teorias comportamentalistas pressupõem que todo ser humano seja tão-somente um caso particular de suas teorias, seja porque está de acordo ou em desacordo com elas. Tratase, portanto, de uma característica que positiva o ser-aí que somos, subtraindo-Ihe seu caráter de poder-ser e a dramaticidade que este caráter impõe ao seu percurso existencial. Por isso, a terapia não enxerga o ser-aí em tudo que vê, pois vê somente a adequação ou inadequação de certos comportamentos em relação ao seu arcabouço conceitual. Isto é signo da presença do caráter especular da verdade, que justifica toda prática terapêutica da psicologia da tradição. Sendo especular, a verdade das psicologias hodiernas pretende dizer o que é - psiquismo humano como tal e no todo, explicando seu funcionamento e produzindo critérios a priori para identificar sua reta atuação. Por isso, todo ser humano é a réplica deste modelo explicativo. Como réplica, pode ou não funcionar segundo sua mais plena condição. Se está em desacordo com tal modelo, a verdade que baliza tal teoria proporciona a justificativa necessária para 0 empreendimento de práticas corretivas. O terapeuta, possuidor da verdade, é aquele que sabe o que o outro necessita para se reintegrar na ordem da qual fugiu. Esta ordem identifica-se com o bem do ser humano, segundo a compreensão prévia do modelo explicativo em questão. Neste sentido, em nome deste bem atua o terapeuta, que é o "funcionário da verdade". Isto assinala o caráter moral de toda prática terapêutica. Em nome do bem, isto é, da plenitude do ser humano expressa na verdade teórica de um certo 
modelo explicativo, atua o terapeuta. Sua ação, portanto, é sempre corretiva e assim o é porque está legitimada pelo caráter especular da verdade, que possui a pretensão de dizer o que é o psiquismo "em si" mesmo. Se Feijoo destaca esta característica da prática clínica não é para corroborá-la, mas para "destruí-la". Disto advém o segundo elemento presente (tacitamente) na crítica de Feijoo à prática clínica presente na tradição, a saber, seu caráter confessional.

"Cabe ao especialista psi dominar, por sua vez, tal subjetividade e, assim, saber como fazer para adaptar o homem ou reduzir suas tensões." Com esta afirmação, Feijoo denuncia a prática confessional inerente à clínica. Basta pensar na psicanálise para entender o que aí está em jogo. A prática psicanalítica, tanto freudiana quanto (sobretudo) lacaniana, parte do pressuposto de que o terapeuta domina o psiquismo humano com a pluralidade de elementos teóricos que fazem parte de sua formação. Ao mesmo tempo, o analisando "sabe" que é o terapeuta que "sabe" qual o seu problema, porque conhece o funcionamento de seu psiquismo, que é somente um exemplar do psiquismo enquanto tal. Consequentemente, 0 analisando supõe que o terapeuta possua a chave para entender 0 que lhe é obscuro: seu inconsciente, que só aparece para aquele que possui as "chaves" teóricas para "abri-lo". Em última instância, o analisado crê que somente o analista pode saber algo sobre uma dimensão sua que de algum modo Ihe é alienada. As palavras, então, são o veículo para que o terapeuta saiba qual "chave" melhor se adéqua à "fechadura" em questão. A palavra, portanto, é sempre um simples aceno para que o terapeuta possa agir e, de algum modo, reinscrever no analisando a verdade de si mesmo - que é a verdade do modelo explicativo do terapeuta - da qual ele mesmo se alienou e para a qual ele não sabe o caminho de volta, pois não possui a "chave" teórica para entender a si mesmo. Isto assinala a presença da confissão na clínica. No fundo, é uma remodelação das práticas confessionais cristãs, com a diferença de que a confissão clínica é mais perigosa que as religiosas. Vejamos.

Confiteri é o termo latino que retrata um exercício peculiar da confissão. Antes de significar a auto-acusação do ser humano perante o juiz divino, a confissão foi, inicialmente, o reconhecimento da fragilidade humana e a disposição para que 0 homem se reencontrasse consigo por intermédio de sua abertura para a fonte divina da qual ele mesmo provém. Deus não é aí o acusador, mas a fonte de libertação através de sua ação misericordiosa. É justamente isto que se vê nas Confissões de Santo Agostinho. No início do livro IX, que, dentre outras coisas, tematiza o tempo e sua relação com a eternidade, Agostinho diz:

Por isso patenteamos o nosso amor para convosco, confessando-vos as nossas misérias e as vossas 
misericórdias a fim de que ponhais termo à obra já começada da nossa libertação e que sejamos felizes em Vós, cessando de ser miseráveis em nós. Por isso nos chamastes para que fôssemos pobres de espírito e mansos, para que chorássemos tendo fome e sede de justiça, para que fôssemos misericordiosos, puros e pacíficos.

Já vos narrei muitas coisas segundo me foi possível e segundo o desejo de minha alma, já que fostes o primeiro a exigir de mim que me confessasse a Vós, meu Senhor e meu Deus, "porque sois bom e a vossa misericórdia é eterna" (AGOSTINHO, 2011, p. 283).

A confissão, como o texto acima deixa claro, é o exercício de autorreconhecimento do homem perante a fonte de sentido realizador de si mesmo: Deus. Por isso, toda fala humana a Deus não é um meio de informação daquilo que ele (Deus) ignora. A finalidade de se falar a Deus não é outra senão " excitar o meu afeto para convosco" (Idem). Como Deus é simultaneamente transcendente e misericordioso, toda confissão não se assegura de Deus, mas possibilita lançar aquele que se confessa nas mãos do mistério divino e, nesta entrega, o homem reconquista sua ipseidade de modo não definitivo (Cf. FILHO, 2009, p. 129-208). Neste sentido, a confissão conta com a verdade da graça divina, que de modo algum pode ser assegurada pelo homem de fé. Há um drama, portanto, no cerne da prática confessional neste momento do cristianismo, que em seguida sofreria uma radical alteração com o sacramento da confissão, orientado pela figura da sacerdote. Com este, a confissão passou a ser o discurso do réu confesso em busca das medidas corretivas que o possibilitassem ser salvo. O sacerdote, por sua vez, tornou-se o agenciador das verdades teológico-morais que deveriam mediatizar o resgate do pecador e o preparar para a graça salvífica de Deus. Começava a entrar em cena as verdades especulares que necessitavam da presença de um especialista (clérigo) para manipulá-la corretivamente. Entretanto, a finalidade desta prática era a salvação da alma, o que dependia da ação gratuita e graciosa de Deus, que não se reduzia à figura do sacerdote. Sempre pairava a dúvida em relação ao fato de se Deus confirmaria efetivamente as medidas sacerdotais, pois Deus mesmo, na condição de ser absoluto, poderia sempre não se adequar por inteiro às práticas humanas. Não é por acaso que a Reforma Protestante, no século XVI, colocou imediatamente em xeque a validade do modo como se praticava o sacramento da confissão. Para a Reforma, tal prática não levaria radicalmente a sério a liberdade da graça divina. Com a clínica psicológica, criticada por Feijoo, a dinâmica corretiva e o aspecto especular da verdade retornam à cena ocidental, sem, entretanto, salvaguardar o caráter de mistério da instância curativa, como se 
pensava em relação a Deus, o que a faz, como afirmado acima, mais perigosa.

A confissão moderna inerente à clínica preserva a figura do sacerdote, porém descarta o mistério divino. Agora, o sacerdote/terapeuta detém os instrumentos de salvação, instrumentos estes que não possuem liberdade, como a graça salvífica de Deus pensada pelo cristianismo, uma vez que se reduzem ao conhecimento do confessor (terapeuta). Se o perdão divino sempre foi um mistério, o "perdão clínico" só é misterioso para o analisando, que desconhece aquele instrumental. Assim, está nas mãos destes sacerdotes modernos a condenação ou a salvação do drama humano, pois eles são os donos dos meios de libertação e dos conhecimentos das perversões humanas. A verdade outrora identificada com Deus agora é nada mais nada menos que os modelos explicativos do funcionamento do psiquismo humano. Por isso, ela tem dono. Resta aos demais se curvarem perante ela e serem modelados e moralizados pelos terapeutas. Assim, na terceira e última parte de $A$ existência para além do sujeito, Feijoo registra, ao descrever a situação existencial de um homem ficticiamente chamado de Paulo, que geralmente o "paciente" vai à clínica esperando a objetivação dos diagnósticos do terapeuta. Deste modo, no enquadramento psicopatológico, ele sente-se confortável com a identidade que ele acredita possuir ao ouvir do terapeuta qual enfermidade psíquica o determina (Cf. FEIJOO, 2011, p. 134-136). Isto indica que, na prática clínica, o sistema de sujeição do homem já foi assimilado por inteiro. Vamos à terapia esperando que nos digam - ou nos façam saber - o que somos e por que assim o somos. Encontramos relativo conforto com esta prática porque de algum modo acreditamos que saltamos por sobre o caráter indeterminado e indeterminável do nosso ser-aí que é sempre poder-ser. Assim, entregamos nossa existência para que decidam por nós o nosso ser, dando crédito às teorias que, a serviço de explicações cabais do nosso psiquismo, subtrai o lastro ontológico que nos determina, lastro este que torna a existência um exercício de conquista e reconquista de si e não a busca por identificação do nosso ser com alguma abstrata natureza (morta) humana.

Ao inscrever a existência, com sua dinâmica performática e "elástica", no cerne da clínica, Feijoo não define de uma vez por todas o modo como se realiza a clínica, mesmo que ela tenha, na última parte do livro, apresentado alguns exemplos de práticas clínicas com enfoque fenomenológico-existencial. O que ela faz é sobretudo apropriar-se desse espaço - a terapia - não para responder os enigmas da existência humana, mas para proporcionar um lugar onde é possível - e não necessário - o acontecimento de transformações existenciais. Estas não são causadas pelo terapeuta, mas somente favorecidas pela sua participação em um espaço (éthos) em que ele não é o 
protagonista, mas um dos personagens. Isto significa dizer que 0 terapeuta e a terapia são elementos de um jogo que abre as portas para a simples possibilidade do acontecimento da reinvenção de si. Enquanto salvaguardador desta simples possibilidade, o terapeuta atinge sua riqueza, mesmo que se mova na precariedade assinalada pela falta de modelos teóricos que expliquem o ser humano. Tarefa que exige um novo aprendizado: esquecer o lugar e função do sacerdote/terapeuta, para conquistar a sabedoria da docta ignorantia daqueles que, ao lado do outro, participam favoravelmente de sua travessia existencial, sem lançar mão de ideias universais de homem e de suas aplicações corretivo-morais na existência alheia. Neste sentido, Feijoo assume a crise da subjetividade para pensar a superação da prática confessional da clínica. Por isso, o livro de Feijoo, intelectual que apresenta grande familiaridade com 0 pensamento fenomenológico-existencial, além de linguagem clara e rigor metodológico, lança à psicologia grandes desafios. Esta é a grande "positividade" desta obra que tem como autora uma das pioneiras e principais pesquisadoras brasileiras da psicologia com bases fenomenológico-existenciais, obra que não visa aniquilar por meio de seus exercícios de destruição da tradição a possibilidade da clínica, mas lança-lhe novos horizontes. Basta saber se há a coragem para se pensar a existência para além do sujeito (supósitos metafísicos) e, assim, entrar na senda dos enigmas existenciais e não das respostas cabais. Alea jacta est - "a sorte está lançada".

\section{Referências}

AQUINO, T. de. "Questões disputadas sobre a verdade". In: Verdade e Conhecimento. São Paulo: Martins Fontes, 2002.

AGOSTINHO, S. Confissões. Petrópolis: Vozes/Editora Universitária São Francisco, 2011.

CASANOVA, M. A. Nada a caminho: Impessoalidade, niilismo e técnica na obra de Martin Heidegger. Rio de Janeiro: Forense Universitária, 2006.

Compreender Heidegger. Petrópolis: Vozes, 2009.

FEIJOO, A. M. L. C. de. A existência para além do sujeito: A crise da subjetividade moderna e suas repercussões para a possibilidade de uma clínica psicológica com fundamentos fenomenológicoexistenciais. Rio de Janeiro: ViaVerita, 2011.

FILHO, M. A. N. A razão em exercício: Estudos sobre a filosofia de Agostinho. São Paulo: Paulus/Discurso Editorial, 2009.

HEIDEGGER, M. Caminhos de floresta. Lisboa: Calouste Gulbekian, 2002.

Conceitos fundamentais da metafísica: mundo, finitude, solidão. Rio de Janeiro: Forense Universitária, 2003. 
Sein und Zeit. Tübingen: Max Niemeyer, 2006.

MARX, K. "Os 18 brumário de Luís Bonaparte". In: Marx. Coleção Os pensadores. São Paulo: Abril Cultural, 1988.

NIETZSCHE, F. Além do bem e do mal - Prelúdio a uma Filosofia do Futuro. Trad. de Paulo César de Souza. São Paulo: Companhia das Letras, 1999.

- Crepúsculo dos Ídolos ou como filosofar com o martelo. Trad. de Marco Antônio Casanova. Rio de Janeiro: Relume Dumará, 2000.

A gaia ciência. Trad. de Paulo César de Souza. São Paulo:

Companhia das Letras, 2003.

\section{Endereço para correspondência}

Alexandre Marques Cabral

Rua Barão de Piracinunga, 62 ( IFEN)

Endereço eletrônico: alxcbrl@yahoo.com.br

Recebido em: 30/03/2012

Reformulado em: 24/07/2012

Aceito para publicação em: 25/07/2012

Acompanhamento do processo editorial: Ana Maria Lopez Calvo de Feijoo

Notas

* Doutorado em filosofia na UERJ. Vinculação institucional: Colégio Federal Pedro II, Instituto Metodista Bennett e Instituto de Psicologia fenomenológico-existencial. 